\title{
Histidine-Tagged Shiga Toxin B Subunit Binding Assay: Simple and Specific Determination of Gb3 Content in Mammalian Cells
}

\author{
In-Sun Shin, ${ }^{a, b}$ Kiyotaka NishiKawA, ${ }^{c, d}$ Hiroki Maruyama, ${ }^{e}$ and Satoshi IshiI ${ }^{*, a}$ \\ ${ }^{a}$ Department of Agricultural and Life Sciences, Obihiro University of Agriculture and Veterinary Medicine; Obihiro \\ 080-8555, Japan: ${ }^{b}$ Course of Science of Bioresources, The United Graduate School of Agricultural Sciences, Iwate \\ University; Morioka 020-8550, Japan: ${ }^{c}$ Department of Clinical Pharmacology, Research Institute, International Medical \\ Center of Japan; Tokyo 162-8655, Japan: ' PRESTO, Japan Science and Technology Agency; Saitama 332-0012, Japan: \\ and ${ }^{e}$ Division of Clinical Nephrology and Rheumatology, Niigata University Graduate School of Medical and Dental \\ Sciences; Niigata 951-8510, Japan.
}

Received November 22, 2005; accepted January 11, 2006; published online January 18, 2006

A two-step binding assay for globotriaosylceramide (Gb3) content was developed by histidine-tagging strategy, which is a well-established method for the purification of recombinant proteins. The complete binding of the recombinant His-tagged Shiga toxin $1 \mathrm{~B}$ subunit (1B-His) $(1 \mu \mathrm{g} / \mathrm{ml})$ to the standard $\mathrm{Gb3}$ adsorbed on a multi-well $\mathrm{H}$ type plate was observed within $30 \mathrm{~min}$ at $37^{\circ} \mathrm{C}$; and its binding could be visualized by the following applications of HisProbe-HRP $(8 \mu \mathrm{g} / \mathrm{ml})$ and tetramethylbenzidine (TMB) peroxidase substrate. The 1B-His binding assay was linear over the range of 1 to $100 \mathrm{ng}$ of $\mathrm{Gb3}$ per well. The binding of 1B-His was specific to Gb3 separated from HeLa cells, and no major cross-reactivity of other glycolipids in Folch's lower fractions extracted from HeLa cells was detected. The glycolipids in Folch's lower fractions from HeLa cells, human fibroblasts and mouse heart were suitable for this assay, but the further purification was needed for glycolipids from human plasma, thus sample preparation is critical factor for the reliable determination of Gb3 content. The 1B-His binding to Gb3 was inhibited by the addition of galactose, but not mannose. This $1 \mathrm{~B}-\mathrm{His}$ binding assay will be useful not only for the determination of Gb3 content, but also for screening for the compounds which inhibit the toxin-binding to Gb3. The strategy of our present method may be applicable for other binding assay, such as Cholera toxin B-subunit for ganglioside GM1.

Key words globotriaosylceramide; Shiga toxin; binding assay method; His-tagged protein

Globotriaosylceramide (Gal $\alpha 1-4 \mathrm{Gal} \beta 1-4 \mathrm{Glc} \beta 1-1 \mathrm{Cer} ; \mathrm{Gb} 3)$ is the major neutral glycosphingolipid accumulating in patients with Fabry disease, which is an inherited disease caused by a deficiency of $\alpha$-galactosidase $\mathrm{A},{ }^{1,2)}$ and is also known as the receptor for the Shiga toxin (Stx, also called verotoxin), which is a class of protein toxin produced by Stxproducing strains of Escherichia coli (STEC) associated with diarrhea, hemorrhagic colitis, ${ }^{3)}$ and hemolytic uremic syndrome (HUS). ${ }^{4,5)}$ Stx is an approximately $70-\mathrm{kDa}$ complex comprised of one A-subunit $(32 \mathrm{kDa})$ and five B-subunits $\left(7.5 \mathrm{kDa}\right.$ each). $\left.{ }^{6}\right)$ The holotoxin binds via $\mathrm{B}$-subunit pentamer with high affinity to the terminal digalactose of $\mathrm{Gb3} 3{ }^{7,8)} \mathrm{Al}-$ though the cytotoxicity of Stx was mainly caused by the Asubunit, which has an RNA- $N$-glycosidase activity, resulting in inhibition of protein synthesis, ${ }^{7)}$ Jacewicz et al. ${ }^{9)}$ suggested that the basal levels of $\mathrm{Gb} 3$ in human cells may relate to their sensitivity toward Stx. The assay of $\mathrm{Gb} 3$ content in mammalian cells is important for the study on the mechanism of Stx-cytotoxicity and on the pathogenesis of Fabry disease.

Various assay methods for $\mathrm{Gb} 3$ content have been previously reported, such as HPLC analysis of benzoylated glycolipids, ${ }^{10)}$ TLC-orcinol staining, ${ }^{11)}$ liquid chromatography/tandem mass spectrometry (LC/MS/MS) analysis, ${ }^{12)}$ and matrixassisted laser desorption ionisation with time-of-flight (MALDI-TOF) mass spectrometry. ${ }^{13)}$ High cost equipment is sometimes required for these methods. In contrast, the simple assay method has been reported as an enzyme-linked immunosorbent assay (ELISA) method using verotoxin B subunit. ${ }^{14)}$ This method has many benefits including no special equipment is required, many samples can be assayed at once, and a specific $\mathrm{Gb} 3$ assay can be accomplished because of the high affinity of the verotoxin B subunit toward Gb3.

The purpose of this study was to simplify the ELISA method using the verotoxin B subunit and to determine the specificity of $\mathrm{Gb} 3$ assay in various sources. In this study, we used the recombinant histidine-tagged B subunit of Stx 1 (1B-His), because 1B-His has a higher affinity toward $\mathrm{Gb} 3$ in comparison with His-tagged Stx 2B subunit (2B-His). ${ }^{15)}$ The two-step binding assay was established by using 1B-His and HisProbe-HRP, which is a nickel $\left(\mathrm{Ni}^{2+}\right)$ activated derivative of horseradish peroxidase (HRP) and is specifically bound to the poly-histidine residue; and the sample preparation of glycosphingolipid suitable for this Gb3 assay was studied in different sources. Other applications of this binding assay were also suggested in this study.

\section{Experimental}

Preparation of Recombinant 1B-His The recombinant 1B-His, in which 6 histidine residues were added at the carboxy termini of the B subunits, was prepared as described previously. ${ }^{15)}$ The BL21DE cells expressing 1B-His were cultured in $300 \mathrm{ml}$ of LB broth (Difco laboratories, Detroit, MI, U.S.A.) supplemented with $50 \mu \mathrm{g} / \mathrm{ml}$ kanamycin (Nacalai Tesque, Inc., Kyoto, Japan) at $37^{\circ} \mathrm{C}$ for $2 \mathrm{~h}$. The cells were subsequently treated with $1.0 \mathrm{mmol} / 1$ isopropyl $\beta$ - $\mathrm{D}(-)$ thiogalactopyranoside (Wako Pure Chemical Industries, Ltd., Osaka, Japan) at $37^{\circ} \mathrm{C}$ for $4 \mathrm{~h}$. Cells were pooled by centrifugation at $6000 \mathrm{rpm}$ for $15 \mathrm{~min}$ at $4{ }^{\circ} \mathrm{C}$. The $1 \mathrm{~B}$-His was extracted from cell pellets with the Bugbuster protein extraction reagent (Novagen, Madison, WI, U.S.A.) and purified by using the His-bind purification kit (Novagen) according to manufacturer's recommendations. Purified 1B-His fractions were applied to an NAP10 column (Amersham Biosciences, Uppsala, Sweden) equilibrated with phosphate-buffered saline (PBS). The purified 1B-His was revealed as a single band on SDS-PAGE (data not shown) and its aliquots were stored at $-20^{\circ} \mathrm{C}$.

Materials HisProbe-HRP was purchased from Pierce Biotechnology, 
Inc. (Rockford, IL, U.S.A.). Purified glycosphingolipids, Gb3 from porcine erythrocytes and globotetraosylceramide (Gb4) from porcine erythrocytes were purchased from Nacalai Tesque, Inc. and Wako Pure Chemical Industries, Ltd., respectively.

Cell Lines and Specimen HeLa cell line (JCRB9004) was purchased from Human Science Research Resources Bank (Osaka, Japan) and human fibroblast cell line was established from a heterozygous patient with Fabry disease. Cells were cultured at $37^{\circ} \mathrm{C}$ in Dulbecco's Modified Eagle's Medium (Sigma-Aldrich, Inc., St. Louis, MO, U.S.A.) supplemented with $10 \%$ fatal calf serum (Biological Industries, Haemek, Israel) under a humidified $5 \% \mathrm{CO}_{2}$ atmosphere. Cultured cells were washed with PBS and then harvested by a plastic scraper. Cells were precipitated by centrifugation at $2000 \mathrm{rpm}$ for $5 \mathrm{~min}$. Human plasma was prepared from the heparinized blood of a heterozygous patient with Fabry disease by centrifugation at $3000 \times \boldsymbol{g}$ for $5 \mathrm{~min}$. All samples were stored at $-20^{\circ} \mathrm{C}$

Glycosphingolipid Extraction Cell pellets and minced heart from an $\alpha$-galactosidase A-knock out (KO) mouse ${ }^{16)}$ were homogenized using a handy micro homogenizer (Physcotron, Niti-on, Inc., Chiba, Japan) in 0.2$\mathrm{ml} \mathrm{H} \mathrm{H}_{2} \mathrm{O}$. After the determination of protein content with a DC Protein Assay kit (Bio-Rad Laboratories, Hercules, CA, U.S.A.), cellular lipids were extracted from homogenates containing $5-10 \mathrm{mg}$ protein with 20 volumes of chloroform-methanol $(2: 1, \mathrm{v} / \mathrm{v})$. The lipid from human plasma was also extracted with 20 -fold excess volume of chloroform-methanol $(2: 1, \mathrm{v} / \mathrm{v})$. Following filtration by $90-\mathrm{mm}$ 5A filter papers (Toyo Roshi Kaisha, Ltd., Tokyo, Japan), crude extracts were dried and stored as a crude extract fraction. Crude extracts were further treated with $1 \mathrm{ml}$ of methanolic $\mathrm{NaOH}$ $\left(0.2 \mathrm{M} \mathrm{NaOH}\right.$ in methanol) at $40^{\circ} \mathrm{C}$ for $2 \mathrm{~h}$. After neutralizing the solution with glacial acetic acid, glycosphingolipids were further subjected to the Folch's partition (chloroform-methanol- $\mathrm{H}_{2} \mathrm{O}, 8: 4: 3$ in v/v/v). ${ }^{17)}$ Glycosphingolipids recovered in the lower phase were pooled and designated as a Folch's lower fraction. The glycosphingolipids in a Folch's lower fraction were further purified by the Iatrobeads (Iatron Laboratories, Tokyo, Japan) column chromatography. Glycosphingolipids suspended in $1 \mathrm{ml}$ of chloroform-methanol $(2: 1, \mathrm{v} / \mathrm{v})$ were applied to an Iatrobeads column $(0.5 \times 2 \mathrm{~cm})$ equilibrated with isopropanol-hexane $(55: 45, \mathrm{v} / \mathrm{v})$. The bound glycolipids were eluted with isopropanol-hexane-water $(55: 30: 15, \mathrm{v} / \mathrm{v} / \mathrm{v})$. Eluates were pooled and used as an Iatrobeads-binding fraction.

Separation of Glycosphingolipids by HPLC Glycosphingolipids in Folch's lower fraction extracted from HeLa cells were separated by HPLC (LC-10AD, Shimadzu Corporation, Kyoto, Japan) according to the method of Kannagi et al. ${ }^{18)}$ Folch's lower fraction from HeLa cells was dissolved in $2 \mathrm{ml}$ of chloroform-methanol $(2: 1, \mathrm{v} / \mathrm{v})$, and applied to a packed column of Iatrobeads (6RS-8010, Iatron Laboratories; $1 \times 50 \mathrm{~cm}$ ) equilibrated with isopropanol-hexane $(55: 45, \mathrm{v} / \mathrm{v})$. Glycosphingolipids were eluted with a gradient of isopropanol-hexane-water from $55: 45: 0$ to $55: 30: 15(\mathrm{v} / \mathrm{v} / \mathrm{v})$. The flow rate was set at $2 \mathrm{ml} / \mathrm{min}$ by applying approximately $60-70 \mathrm{kgf} / \mathrm{cm}^{2}$. Fractions were collected by a fraction collector (FC 203B, Gilson Inc., Middleton, WI, U.S.A.) at 2-min intervals and the total volume of eluate was $400 \mathrm{ml}$. Each fraction was dried and resuspended in chloroform-methanol $(2: 1, \mathrm{v} / \mathrm{v})$. A small aliquot of each fraction was applied to TLC analysis, and 7 major lipid components were pooled in 7 fractions.

1B-His Binding Assay The 1B-His binding assay for the determination of Gb3 content was performed as follows. Samples containing glycosphingolipids in $10 \mu \mathrm{l}$ of $100 \%$ methanol were plated onto a multi-well $\mathrm{H}$ type plate (Sumitomo Bakelite Co., Ltd., Tokyo, Japan). The plates were placed to evaporate methanol at room temperature for $1 \mathrm{~h}$, and then $200 \mu \mathrm{l}$ of $1 \%$ bovine serum albumin solution in PBS (BSA-PBS) was added to each well and incubated at $37^{\circ} \mathrm{C}$ for $1 \mathrm{~h}$. Plates were washed once with $400 \mu \mathrm{l}$ of $0.2 \%$ BSA-PBS, and then incubated with purified $1 \mathrm{~B}-\mathrm{His}(1 \mu \mathrm{g} / \mathrm{ml})$ in $0.2 \%$ BSAPBS at $37^{\circ} \mathrm{C}$ for $30 \mathrm{~min}$. Following washing three times with $200 \mu \mathrm{l}$ of PBS, the plates were incubated with the HisProbe-HRP $(8 \mu \mathrm{g} / \mathrm{ml})$ in $0.2 \%$ BSAPBS at $37^{\circ} \mathrm{C}$ for $30 \mathrm{~min}$. The plates were washed with $200 \mu \mathrm{l}$ of PBS and then visualized with tetramethylbenzidine (TMB) peroxidase substrate system (100 $\mu \mathrm{l} /$ well) (KPL, Gaithersburg, MD, U.S.A.) at room temperature for $10-15 \mathrm{~min}$. Reactions were terminated by the addition of $100 \mu 1$ of $1 \mathrm{M}$ phosphoric acid and gentle shaking. The absorbance of each well at $415 \mathrm{~nm}$ was determined using a micro plate reader (MPR-A4, Tosoh Co., Tokyo, Japan). For the determination of Gb3 content, 10-100 ng of standard Gb3 was consistently applied on the same plate, and absorbances were determined at each assay.

TLC and TLC-Blotting TLC analysis was quantitatively performed with high-performance TLC (HPTLC)-Silica gel 60 plates (Merck \& Co., Inc., Whitehouse Station, NJ, U.S.A.) using a solvent system of chloroform-methanol-water $(60: 35: 8, \mathrm{v} / \mathrm{v} / \mathrm{v})$. Glycosphingolipids were visual- ized by spraying orcinol-sulfuric acid reagent; and their band intensities were determined by the image processing software Scion Image (Scion Corporation, Frederick, MD, U.S.A.). TLC-blotting with 1B-His was performed by the method of Taki et al. ${ }^{19)}$ Glycosphingolipids were separated on a TLC plate as described above. The plate was sunk in $0.4 \%$ polyisobutylmethacrylate (PIM) solution (2.5\% PIM in chloroform was diluted to $0.4 \%$ with hexane) and followed by blocking with $1 \%$ BSA-PBS. After incubation with $1 \mathrm{~B}-\mathrm{His}$ at $1 \mu \mathrm{g} / \mathrm{ml}$ at room temperature for $30 \mathrm{~min}$, the plate was washed with PBS. After further incubation with HisPorbe-HRP at $8 \mu \mathrm{g} / \mathrm{ml}$ at room temperature for $1 \mathrm{~h}$ and the following final washing, 1B-His binding was visualized with an enhanced chemiluminescent substrate (Pierce Biotechnology, Inc.).

\section{Results}

1B-His Binding Assay with Standard Glycosphingolipids To establish the 1B-His binding assay, we first used standard glycosphingolipids ( $\mathrm{Gb3}$ and $\mathrm{Gb} 4$ ) in the amount of $1-100 \mathrm{ng} /$ well (Fig. 1). Absorbance (abs.) at $415 \mathrm{~nm}$ and amount of Gb3 were good corresponding in the range of 1 to $100 \mathrm{ng}$ of Gb3. 1B-His binding was partially observed when a higher amount of Gb4 was used. One hundred nanograms of Gb4 showed 0.062 abs. units; and 7.5\% of 0.823 abs. units was observed with $100 \mathrm{ng}$ of Gb3. The assay was highly reproducible, had a very low background $(<0.05$ abs. units $)$, and there was minimal variation between three independent determinations for each Gb3 concentration. The effect of incubation time on 1B-His binding to standard Gb3 was analyzed. The $1 \mathrm{~B}-H i$ s solution $(1 \mu \mathrm{g} / \mathrm{ml})$ in $0.2 \%$ BSA-PBS was applied to multi-well $\mathrm{H}$ type plates, coated with standard Gb3 $(100 \mathrm{ng})$, and incubated for 5 different lengths $(10,20,30,60,120 \mathrm{~min})$ at $37^{\circ} \mathrm{C}$. The $1 \mathrm{~B}$-His binding was low for the shortest incubation, and reached a plateau at $30 \mathrm{~min}$; and the effect of incubation time on the 1B-His binding was similar for lower Gb3 content (data not shown). This data suggested that at least 30-min incubation at $37^{\circ} \mathrm{C}$ was necessary for the completion of $1 \mathrm{~B}$-His binding to Gb3. In Fig. 2, the optimum concentration of 1B-His and HisProbe-HRP was determined. The Gb3-dependent binding of 1B-His increased, according to the concentration of $1 \mathrm{~B}-$ His, and reached a plateau at $1 \mu \mathrm{g} / \mathrm{ml}$ (Fig. 2A). 1B-His binding activity was also dependent on the addition of HisProbeHRP, and reached a plateau at $8 \mu \mathrm{g} / \mathrm{ml}$ (Fig. 2B). These data indicated that the optimum concentrations of $1 \mathrm{~B}-\mathrm{His}$ and HisProbe-HRP for the detection of $\mathrm{Gb} 3$ content were $1 \mu \mathrm{g} / \mathrm{ml}$ and $8 \mu \mathrm{g} / \mathrm{ml}$, respectively.

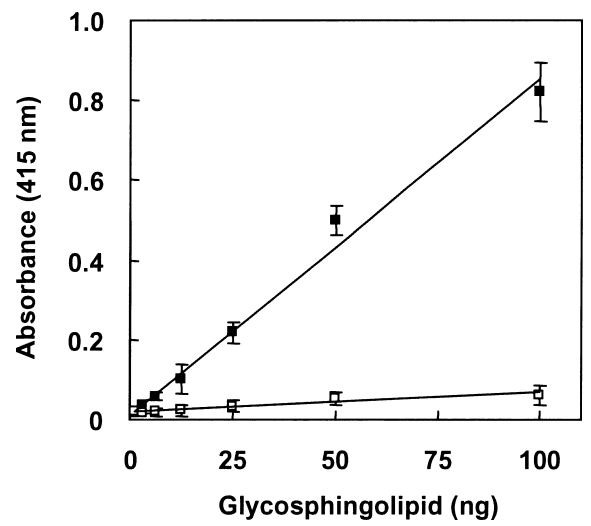

Fig. 1. 1B-His Binding Assay with Standard Glycosphingolipids

Doubled dilutions of standard Gb3 $(\mathbf{\square})$ and Gb4 $(\square)$ were applied to a multi-well H type plate and assayed with $1 \mu \mathrm{g} / \mathrm{ml} 1 \mathrm{~B}-H i s$ and $8 \mu \mathrm{g} / \mathrm{ml}$ HisProbe-HRP. Results are the mean \pm S.D. of three independent assays 
Specificity of the 1B-His Binding Assay In order to determine the specificity of the 1B-His binding assay, Folch's lower fraction from HeLa cells was used as the source of various lipids. As shown in Fig. 3A, more than 6 different glycolipids and a group of cholesterol were present in this fraction. All major lipid components were separated by an HPLC
A

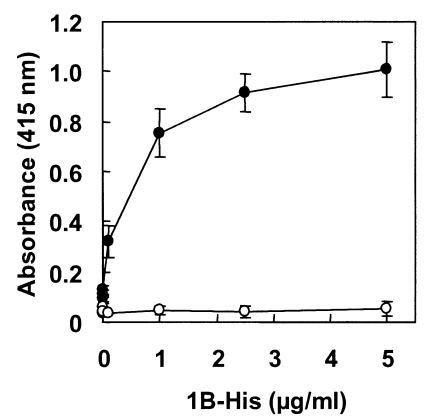

B

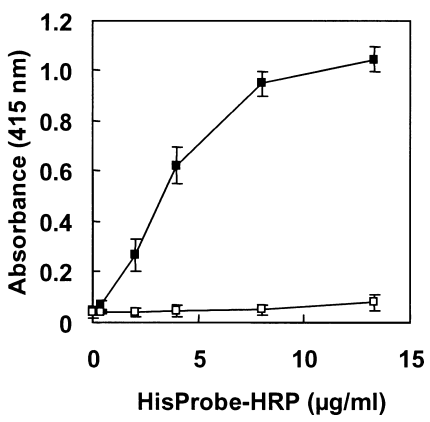

Fig. 2. Optimum Concentration of 1B-His (A) and HisProbe-HRP (B)

In $\mathrm{A}$, wells with $(-)$ or without $(\bigcirc) 100 \mathrm{ng}$ of standard $\mathrm{Gb3}$ were treated with indicated concentrations of 1B-His for $30 \mathrm{~min}$. Bound 1B-His was detected by $8 \mu \mathrm{g} / \mathrm{ml}$ HisProbe-HRP. In B, wells coated with $100 \mathrm{ng}$ of Gb3 were treated with (ם) or without ( $\square$ ) $1 \mu \mathrm{g} / \mathrm{ml}$ of $1 \mathrm{~B}-$ His. Bound 1B-His was determined by indicated concentrations of HisProbe-HRP. The error bars represent S.D. $(n=3)$. attached Iatrobeads column, and pooled into 7 fractions (Fig. $3 \mathrm{~A})$. Fraction 1 was the pass through fraction using Iatrobeads column chromatography, and Fractions 2 to 7 were once bound and then eluted with different solvent conditions. The highest abs. units (1.238) in 1B-His binding was observed in Fraction 5, which contained Gb3. A partial 1B-His binding ( 0.104 abs. units) was detected in Fraction 6, which contained $\mathrm{Gb} 4$, but other fractions were less than background level ( $<0.05$ abs. units) (Fig. 3B). To clarify whether the presence of non-Gb3 lipids negatively or positively affect the 1B-His binding assay, all 6 fractions other than Fraction 5 were combined, and a different concentration of standard Gb3 (Fig. 4A) was added to the pooled lipids (Fig. 4B). The abs. unit in the 1B-His binding simply corresponded to the content of standard $\mathrm{Gb} 3$, and no significant difference was observed between samples with or without combined lipids (Fig. 4C). These data indicated that no marked effect of other lipids on the 1B-His binding assay and low Gb3 content in HeLa cells can be correctly determined. The specificity of the 1B-His binding was further determined by TLC-blotting (Fig. 5). Iatrobeads-binding fractions from human cells, human plasma and KO-mouse heart were applied to TLC plate. More than 5 kinds of neutral glycolipids were detected in all Iatrobeads-binding fractions by the orcinol-staining

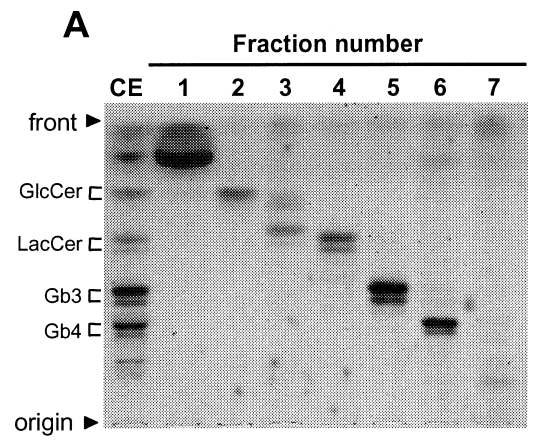

B

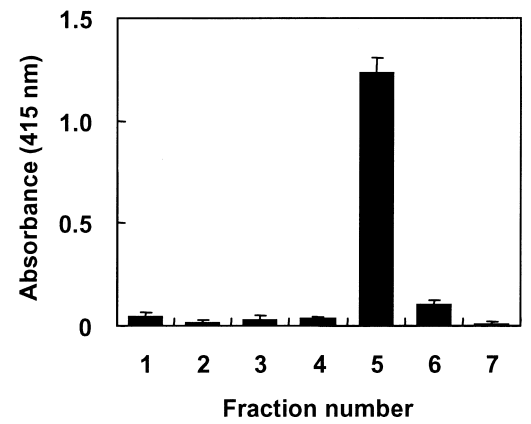

Fig. 3. 1B-His Binding to Glycosphingolipids Fractionated by HPLC from HeLa Cells

In A, glycosphingolipids in Folch's lower fraction extracted from HeLa cells were separated through low-pressure HPLC on an Iatrobeads 6RS-8010 column. TLC analysis was quantitatively performed with a solvent system of chloroform-methanol-water $(60: 35: 8)$, and glycosphingolipids were visualized by orcinol reagent as described in Experimental. $\mathrm{CE}$ is crude extract in Folch's lower fraction extracted from HeLa cells. In B, the 1B-His binding assay of each glycosphingolipid fraction was performed. 1/10 aliquot of each fraction suspended in $100 \mu \mathrm{l}$ of methanol was applied on a multi-well $\mathrm{H}$ type plate, and assayed as described in the legend to Fig. 1. Experiments were performed in triplicate, and the means \pm S.D. of the values are indicated.

A

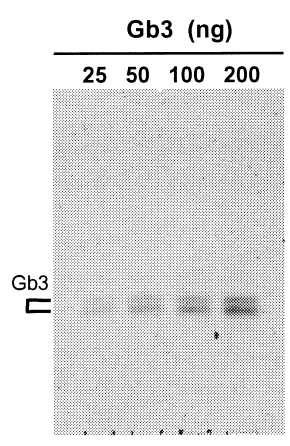

B

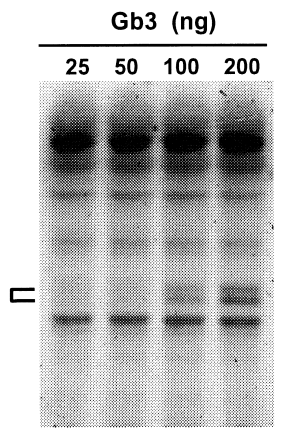

C

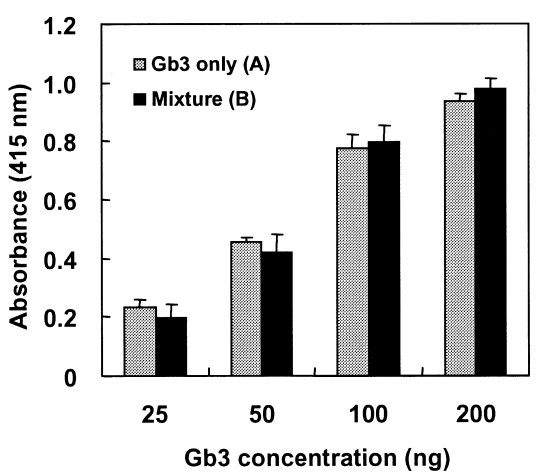

Fig. 4. Effect of All Components Other Than Gb3 in Folch's Lower Fraction from HeLa Cells on the 1B-His Binding Assay

Standard Gb3 at indicated concentrations with (B) or without (A) all components other than Gb3 in Folch's lower fraction from HeLa cells were applied onto TLC, and after its development with chloroform-methanol-water $(60: 35: 8)$ TLC plates were stained with orcinol reagent. In C, the 1B-His binding assay of the same samples used in A and B was performed as described in the legend to Fig. 1. Experiments were performed in triplicate and the means \pm S.D. of the values indicated. 
(Fig. 5A). 1B-His strongly bound to Gb3 in all samples, and weak binding to Gb4 was also observed in HeLa and human fibroblasts; but no other binding was observed in the glycolipids from human and mouse sources (Fig. 5B).

Effect of Sample Preparation on the 1B-His Binding Assay For a practical application of the 1B-His binding assay, the effect of a sample preparation on the assay condition was studied (Fig. 6). The glycolipids were sequentially prepared from human cells and plasma, and mouse tissue, and pooled as a crude extract fraction, a Folch's lower fraction and an Iatrobeads-binding fraction. All Iatrobeads-binding fractions showed good correlation between sample concentration and the 1B-His binding, but no correlation was observed in all crude extract fractions. Although Folch's lower fraction from human plasma did not show linear correlation, Folch's lower fractions from human cells and mouse tissue corresponded well with Iatrobeads-binding fractions from respective sources. This data indicated that a Folch's lower fraction may be suitable preparation for the 1B-His binding assay, but not for human plasma.

Comparison with Another Assay Method Gb3 content was determined in 4 different sources by the 1B-His binding
A

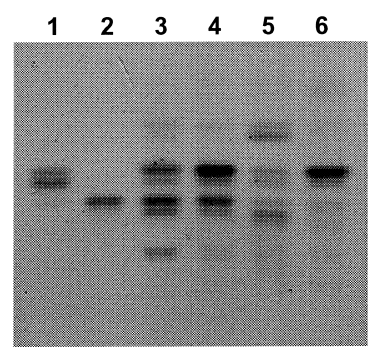

B

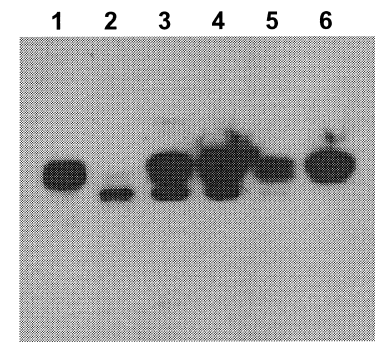

Fig. 5. 1B-His Binding on Glycosphingolipids Separated by TLC of Iatrobeads-Binding Fractions from Human Cells and Plasma, and Mouse Heart

Glycosphingolipid samples were applied to a HPTLC plate, and separated by a solvent system of chloroform : methanol: water $(60: 35: 8)$. After the fixation of the plate with $0.4 \%$ PIM solution, TLC-blotting with 1B-His (B) was performed as described in Experimental. After the determination of 1B-His binding with chemiluminescent substrate, the same TLC plate was stained with orcinol reagent (A). Lanes 1 and 2, 500 ng of standard $\mathrm{Gb} 3$ and $\mathrm{Gb} 4$, respectively; lanes 3, 4, 5 and 6, Iatrobeads-binding fractions from HeLa cells, human fibroblasts, human plasma and the heart from KO mouse, respectively.
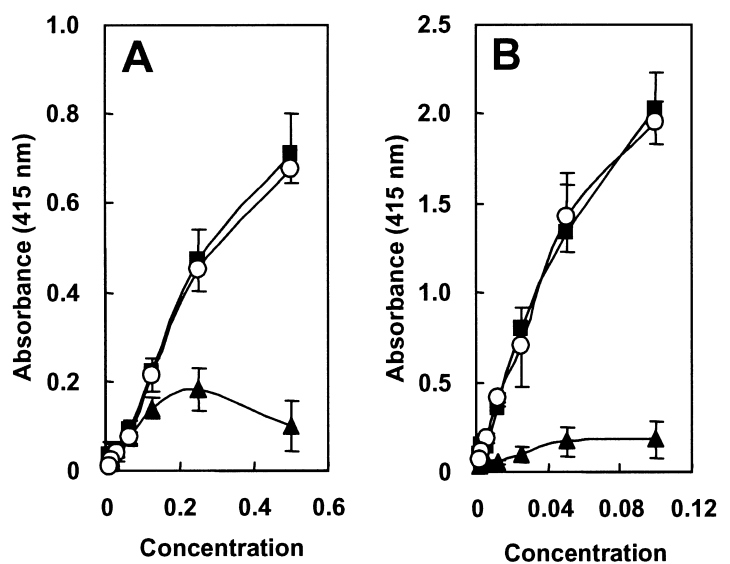

assay and the results were compared to the data from the TLC-orcinol method (Table 1). The mean of Gb3 content determined by the 1B-His binding assay in HeLa cells, human fibroblasts and human plasma from a heterozygous patient with Fabry disease, and a heart from a $\mathrm{KO}$ mouse $(27.3 \mu \mathrm{g} /$ $\mathrm{mg}$ protein, $37.4 \mu \mathrm{g} / \mathrm{mg}$ protein, $11.1 \mu \mathrm{g} / \mathrm{ml}$ and $7.5 \mu \mathrm{g} / \mathrm{mg}$ protein, respectively), corresponded well with the values measured by the TLC-orcinol method $(25.9 \mu \mathrm{g} / \mathrm{mg}$ protein, $34.7 \mu \mathrm{g} / \mathrm{mg}$ protein, $13.9 \mu \mathrm{g} / \mathrm{ml}$ and $6.3 \mu \mathrm{g} / \mathrm{mg}$ protein, respectively). Although the TLC-orcinol method was reproducible, a high amount of Gb3 (100_500 ng) was necessary for the assay; while, $10-50 \mathrm{ng}$ Gb3 was enough for the $1 \mathrm{~B}$ His binding assay.

Other Applications of the 1B-His Binding Assay Blocking of 1B-His binding to Gb3 occurred with the addition of a high concentration of galactose but not mannose (Fig. 7). The abs. unit was decreased to $40 \%$ of the control by the addition of $300 \mathrm{~mm}$ galactose. These inhibition data indicated that $1 \mathrm{~B}-\mathrm{His}$ binding to $\mathrm{Gb} 3$ was specific to galactose.

The possibility that the 1B-His binding assay will be applicable to the measurement of Gb3 synthase ( $\alpha 1,4$-galactosyltransferase) activity was studied. HeLa-cell homogenate was incubated with $0.5 \mathrm{~mm}$ UDP-Gal and $0.2 \mathrm{~mm}$ lactosylceramide (LacCer) at $37^{\circ} \mathrm{C}$ for the indicated period. Folch's lower fraction was then prepared from each reaction solution and $\mathrm{Gb} 3$ content determined by the 1B-His binding assay (Fig. 8). The increase in Gb3 content was 3.2, 6.8, and 9.4 $(\mu \mathrm{g} / \mathrm{mg}$ protein), after incubation for 1,2 and $4 \mathrm{~h}$, respec-

Table 1. Comparison with Gb3 Contents Determined by the Assay Methods of TLC-Orcinol and the 1B-His Binding

\begin{tabular}{lrr}
\hline \multicolumn{1}{c}{ Sample } & TLC-orcinol & 1B-His binding \\
\hline HeLa cells & $25.89 \pm 2.94$ & $27.28 \pm 0.88$ \\
Human fibroblasts & $34.68 \pm 3.08$ & $37.36 \pm 0.64$ \\
Human plasma & $13.91 \pm 2.66$ & $11.13 \pm 1.70$ \\
Mouse heart & $6.28 \pm 1.58$ & $7.52 \pm 0.57$
\end{tabular}

Folch's lower fractions of human cells and mouse heart, and the Iatrobeads-binding fraction of human plasma were used as sample sources for both assays. The determination of $\mathrm{Gb} 3$ content by the TLC-orcinol and 1B-His binding assays was performed as described in Experimental. Values are expressed as $\mu \mathrm{g} / \mathrm{mg}$ of protein \pm S.D. for human cells and mouse heart, and as $\mu \mathrm{g} / \mathrm{ml}$ of plasma \pm S.D. for human plasma.

Fig. 6. Effect of Preparation of Lipid Samples on 1B-His Binding Assay
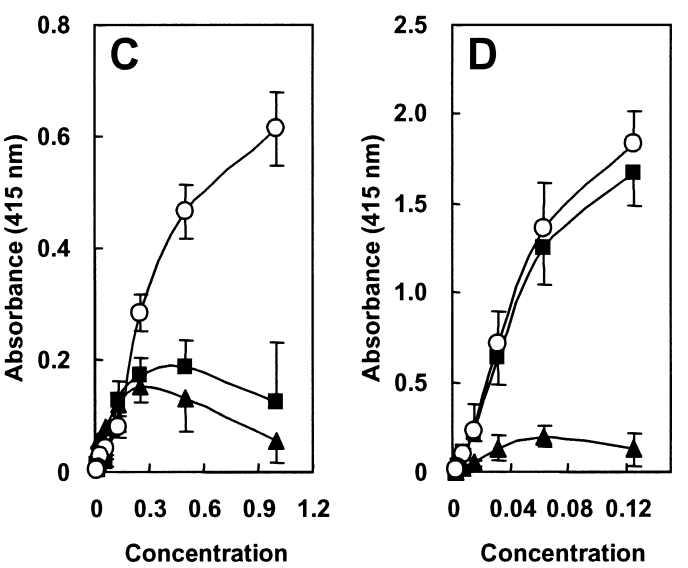

Lipids were extracted from HeLa cells (A), human fibroblasts (B), human plasma (C) and heart from KO mouse (D). Preparation of crude extract fraction (A), Folch's lower fraction $(\mathbf{\square})$ and Iatrobeads-binding fraction $(\bigcirc)$ was performed as described in Experimental. Doubled dilutions of lipid samples were dried on the plate and then assayed by $1 \mathrm{~B}-$ His binding. Concentration 1 was corresponding to $5 \mathrm{ng}$ protein content of HeLa cells, fibroblasts, mouse heart and $5 \mu \mathrm{l}$ of human plasma. Results are mean \pm S.D. 
A

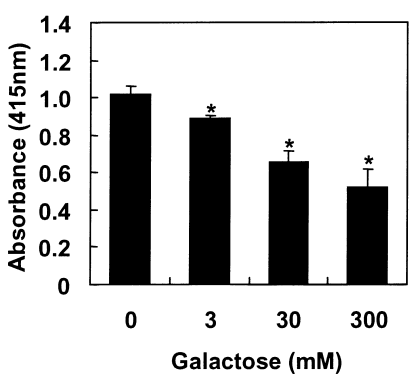

B

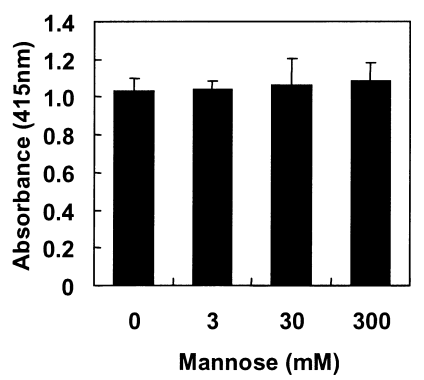

Fig. 7. Effect of Galactose and Mannose Addition in 1B-His Binding

1B-His in $0.2 \%$ BSA-PBS solutions $(1 \mu \mathrm{g} / \mathrm{ml})$ containing galactose (A) or mannose (B) at indicated concentrations was applied to a plate coated with $100 \mathrm{ng}$ of standard $\mathrm{Gb} 3$. After incubation at $37^{\circ} \mathrm{C}$ for $30 \mathrm{~min}$, bound $1 \mathrm{~B}$-His was assayed as described in the legend to Fig. 1. Data represent mean \pm S.D. of three different experiments per point. $* p<0.05$ (compared with concentration $=0$ )

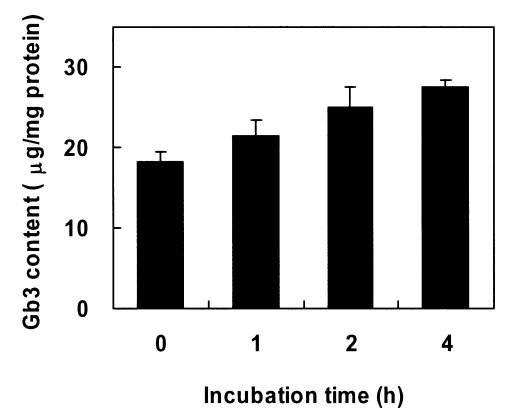

Fig. 8. The Application for Gb3 Synthase Assay

$100 \mu$ of homogenate from HeLa cells $\left(5 \times 10^{6}\right)$ was incubated at $37^{\circ} \mathrm{C}$ in assay mixture containing $25 \mathrm{~mm}$ citrate/phosphate (pH 6.0), $10 \mathrm{mM} \mathrm{MgCl}_{2}, 0.2 \mathrm{~mm}$ LacCer, $0.3 \%$ Triton X-100, 3 mm phosphatidylglycerol, 0.5 mm UDP-Gal. Folch's lower fractions extracted from incubated samples were applied to a multi-well $\mathrm{H}$ type plate, and the $\mathrm{Gb}^{3}$ content was standardized by the protein amount. The error bars represent the S.D. of independent assays $(n=5)$

tively. The linearity of the enzyme reaction was observed until $2 \mathrm{~h}$ of incubation. Gb3 synthase activity in HeLa cells was calculated at $2 \mathrm{~h}$ incubation as $3.4 \mu \mathrm{g}$ of $\mathrm{Gb} 3$ production $/ \mathrm{h} / \mathrm{mg}$ protein. This result indicates that the $1 \mathrm{~B}$-His binding assay may be applicable for the determination of $\mathrm{Gb3}$ synthase activity.

\section{Discussion}

Recent studies on Stx 1B structure revealed that three sites may be involved in the recognition of $\mathrm{Gb}^{20)}$; and one of the 3 sites around Phe 30 might play an important role for the high affinity toward $\mathrm{Gb} 3$ binding. ${ }^{21)}$ Although $\mathrm{AB}_{5}$ class toxin is a complex of an A-subunit and $5 \mathrm{~B}$-subunits, the stability and structure of B-subunits were not altered by the binding of the A-subunit, ${ }^{22}$ and the intracellular trafficking of B-subunits was independent of the A-subunit. ${ }^{23)}$ From the above information, 6 histidine residues at the carboxy termini of His-tagged Stx B may not disturb its binding. We used 1BHis for the detection of $\mathrm{Gb} 3$ because a higher affinity of 1BHis toward Gb3 was observed in comparison with $2 \mathrm{~B}$-His. ${ }^{15}$ The His-tagging strategy is useful for the purification of recombinant proteins ${ }^{24)}$ and we tried to apply for their detection in our present study. HisProbe-HRP is a unique product for the detection of His-tagged protein. Both 1B-His and HisProbe-HRP provide us simple and specific methods for the determination of $\mathrm{Gb} 3$ content. The strategy of this assay method may be applicable for other binding assays, such as

Cholera toxin B-subunit for ganglioside GM1. ${ }^{25)}$

Although the ELISA method using verotoxin B subunit for the determination of $\mathrm{Gb} 3$ content was already established, ${ }^{14)}$ the assay procedure in our method (only two-step binding procedure) was simpler than the ELISA method (three steps). We believe minimum steps in a procedure have benefits not only for the quick assay but also for the specific assay. In a paper by Zeidner et al. ${ }^{14)}$ cross reactivity was determined only with some glycosphingolipids (glucosylceramide, LacCer and Gb4); however we determined the effect of all components in Folch's lower fraction and proved the specificity of our assay method for Gb3 in HeLa cells (Fig. 4), and proved its specificity. For the practical application, we also determined the effect of sample preparation on the 1B-His binding assay. Surprisingly, the sample preparation was critical for the correct determination of $\mathrm{Gb3}$ content by the 1B-His binding assay (Fig. 6). Folch's lower fraction was a suitable preparation for determination in human cells and mouse heart, but further purification was needed in human plasma. Correct binding may be disturbed by lipids other than glycosphingolipids in human plasma. We also confirmed that more than $95 \%$ of $\mathrm{Gb3}$ in HeLa cells was recovered in Folch's lower fraction by the TLC-orcinol method (data not shown). From this information, we concluded that a simple and specific determination of $\mathrm{Gb} 3$ content in HeLa cells can be performed by 1B-His binding assay with Folch's lower fraction.

$\mathrm{Gb} 3$ is one of the potential glycosphingolipid receptors for Stx. ${ }^{26)}$ The cytotoxicity of Stx is highly selective toward cells that express $\mathrm{Gb} 3$ on the cell surface; and it is widely believed that endothelial cells expressing Gb3 are the main targets for Stx in STEC infection. ${ }^{27,28)}$ To prevent Stx cytotoxicity, Stx absorbents or binding neutralizers have been developed and were studied for clinical application. ${ }^{29-31)}$ In our present study, 1B-His binding with Gb3 was blocked by galactose but not mannose (Fig. 7). This data indicated that this 1B-His binding method can be applicable for the screening of Stxbinding neutralizer.

Another application of 1B-His binding was described in Fig. 8. The assay of Gb3 synthase activity was usually performed with radioactive materials. ${ }^{32,33)}$ Our present study indicated that a non-radioactive assay may be possible with the 1B-His binding assay, because the increase in $\mathrm{Gb} 3$ content was linear up to $2 \mathrm{~h}$.

In this study, we established a new Gb3 assay method using a recombinant His-tagged Stx 1B-subunit. The data were reproducible and it was proved that a specific assay can be performed with Folch's lower fraction from HeLa cells. This simple and specific Gb3 assay method is very useful for the determination of effectiveness of various approaches for the treatment of Fabry disease. Recently, we described a new therapeutic strategy, active-site specific chaperone therapy for this disease. ${ }^{34,35)}$ The assay method established by this study will provide a crucial benefit for the preclinical and clinical trial of this treatment strategy. Knowledge of the physiological and pathological role of Gb3 will increase using this assay method.

Acknowledgments This work was supported in part by a research grant from the Ministry of Health, Labour and Welfare of Japan (S.I.). 


\section{References}

1) Brady O. R., Gal A. E., Bradley R. M., Martensson E., Warshaw A. L., Laster L., N. Engl. J. Med., 276, $1163-1167$ (1967).

2) Desnick R. J., Ioannou Y. A., Eng C. M., "The Metabolic and Molecular Bases of Inherited Disease," ed. by Scriver C. R., Beaudet A. L. Sly W. S., Valle D., McGraw-Hill, New York, 2001, pp. 3733-3774.

3) Riley L. W., Remis R. S., Helgerson S. D., McGee H. B., Wells J. G., Davis B. R., Hebert R. J., Olcott E. S., Johnson L. M., Hargett N. T., Blake P. A., Cohen M. L., N. Engl. J. Med., 308, 681-685 (1983).

4) Karmali M. A., Petric M., Lim C., Fleming P. C., Arbus G. S., Lior H., J. Infect. Dis., 151, 775-782 (1985).

5) Kaplan B. S., Cleary T. G., Obrig T. G., Pediatr. Nephrol., 4, 276-283 (1990).

6) Fraser M. E., Chernaia M. M., Kozlov Y. V., James M. N., Nat. Struct. Biol., 1, 59-64 (1994)

7) Lingwood C. A., Law H., Richardson S., Petric M., Brunton J. L., De Grandis S., Karmali M., J. Biol. Chem., 262, 8834-8839 (1987).

8) Waddell T., Head S., Petric M., Cohen A., Lingwood C., Biochem. Biophys. Res. Commun., 152, 674-679 (1988).

9) Jscewicz M., Feldman H. A., Donohue-Rolfe A., Balasubramanian K. A., Keusch G. T., J. Infect. Dis., 159, 881—889 (1989).

10) McCluer R. H., Williams M. A., Gross S. K., Meisler M. H., J. Biol. Chem., 256, 13112-13120 (1981)

11) Takahashi H., Hirai Y., Migita M., Seino Y., Fukuda Y., Sakuraba H., Kase R., Kobayashi T., Hashimoto Y., Shimada T., Proc. Natl. Acad. Sci. U.S.A., 99, 13777-13782 (2002).

12) Wilcox W. R., Banikazemi M., Guffon N., Waldek S., Lee P., Linthorst G. E., Desnick R. J., Germain D. P., Am. J. Hum. Genet., 75, 65-74 (2004).

13) Touboul D., Roy S., Germain D. P., Bailler A., Brion F., Prognon P., Chaminade P., Laprevote O., Anal. Bioanal. Chem., 382, 1209-1216 (2005).

14) Zeidner K. M., Desnick R. J., Ioannou Y. A., Anal. Biochem., 267, 104-113 (1999).

15) Watanabe M., Matsuoka K., Kita E., Igai K., Higashi N., Miyagawa A., Watanabe T., Yanoshita R., Samejima Y., Terunuma D., Natori Y., Nishikawa K., J. Infect. Dis., 189, 360-368 (2004).

16) Ohshima T., Murray G. J., Swaim W. D., Longenecker G., Quirk J. M.,
Cardarelli C. O., Sugimoto Y., Pastan I., Gottesman M. M., Brady R. O., Kulkarni A. B., Proc. Natl. Acad. Sci. U.S.A., 94, 2540-2544 (1997).

17) Folch J., Lees M., Sloane-Stanley G. H., J. Biol. Chem., 226, 497509 (1957).

18) Kannagi R., Watanabe K., Hakomori S., Methods Enzymol., 138, $3-$ 13 (1987)

19) Taki T., Ishikawa D., Ogura M., Nakajima M., Handa S., Cancer Res., 57, 1882-1888 (1997)

20) Ling H., Boodhoo A., Hazes B., Cummings M. D., Armstrong G. D., Brunton J. L., Read R. J., Biochemistry, 37, 1777-1788 (1998).

21) Soltyk A. M., MacKenzie C. R., Wolski V. M., Hirama T., Kitov P. I., Bundle D. R., Brunton J. L., J. Biol. Chem., 277, 5351-5359 (2002).

22) Goins B., Freire E., Biochemistry, 27, 2046-2052 (1988).

23) Sandvig K., Ryd M., Garred O., Schweda E., Holm P. K., van Deurs B., J. Cell Biol., 126, 53 - 64 (1994).

24) Hoffmann A., Roeder R. G., Nucleic Acids Res., 19, 6337-6338 (1991).

25) Pina D. G., Johannes L., Toxicon, 45, 389-393 (2005).

26) Lingwood C. A., Trends Microbiol., 4, 147-153 (1996).

27) Kaye S. A., Louise C. B., Boyd B., Lingwood C. A., Obrig T. G., Infect. Immun., 61, 3886-3891 (1993).

28) Ohmi K., Kiyokawa N., Takeda T., Fujimoto J., Biochem. Biophys. Res. Commun., 251, 137-141 (1998).

29) Armstrong G. D., Fodor E., Vanmaele R., J. Infect. Dis., 164, 11601167 (1991).

30) Kitov P. I., Sadowska J. M., Mulvey G., Armstrong G. D., Ling H., Pannu N. S., Read R. J., Bundle D. R., Nature (London), 403, 669$672(2000)$

31) Paton A. W., Morona R., Paton J. C., Nat. Med., 6, 265-270 (2000).

32) Taniguchi N., Yanagisawa K., Makita A., Naiki M., J. Biol. Chem., 260, 4908-4913 (1985)

33) Keusch J. J., Manzella S. M., Nyame K. A., Cummings R. D., Baenziger J. U., J. Biol. Chem., 33, 25308-25314 (2000).

34) Fan J.-Q., Ishii S., Asano N., Suzuki Y., Nat. Med., 5, 112-115 (1999).

35) Ishii S., Yoshioka H., Mannen K., Kulkarni A. B., Fan J. Q., Biochim. Biophys. Acta, 1690, 250-257 (2004). 